\title{
On Negative Imperatives in Korean
}

\author{
Chung-hye Han \\ Dept. of Linguistics \\ Simon Fraser University \\ 8888 University Drive \\ Burnaby BC V5A 1S6, Canada \\ chunghye@sfu.ca
}

\author{
Chung-min Lee \\ Dept. of Linguistics \\ and Cognitive Science Program \\ Seoul National Univeristy \\ Seoul 151-742, Korea \\ clee@snu.ac.kr
}

\begin{abstract}
In this paper, we address two questions concerning negative imperatives in Korean: . (i) what is the morpho-syntactic nature of mal in negative imperatives?; and (ii) why is it impossible to form negative imperatives with short negation an? We will argue that the clause structure of imperatives include a projection of deontic modality and a projection of imperative operator encoding illocutionary force, and that mal is a lexicalization of long negation and deontic modality. We then propose that a negative imperative with short negation is ruled out because such construction maps onto incoherent interpretation which can be spelled out as I direct you to bring about a negative state or a negative event.
\end{abstract}

\section{Issues}

Korean has two forms of negation: long form and short form. The long form negation occurs after the verb and must be followed by the light verb $h a$, as in (1a). The short form occurs before the verb, as in (1b).

(1) a. Inho-nun hakkyo-ey ka-ci ani ha-yess-ta. Inho-Top school-to go-Ci Neg ha-Past-Decl 'Inho did not go to school.

b. Inho-nun hakkyo-ey an ka-ss-ta. Inho-Top school-to Neg go-Past-Decl 'Inho did not go to school.

Negative imperatives however cannot be formed with short form. The type of negation in negative imperatives is basically the long form type, but its lexical form mal is different from the usual form ani.

(2) a. * hakkyo-ey ka-ci ani ha-yela. school-to go-Ci Neg ha-Imp 'Don't go to school.'

b. * hakkyo-ey an ka-la. school-to Neg go-Imp 'Don't go to school.'

c. hakkyo-ey ka-ci mal-ala. school-to go-Ci Neg-Imp 'Don't go to school.' 
In this paper, we address two questions concerning negative imperatives in Korean: (i) what is the morpho-syntactic nature of mal in negative imperatives?; and (ii) why is it impossible to form negative imperatives with short negation an? The answer to the question why negative imperatives cannot be formed with long negation ani will follow naturally from our analysis of mal.

In section 2, our discussion on mal will lead us to the conclusion that the clause structure of imperatives include a projection of deontic modality and a projection of imperative operator encoding illocutionary force, and that $\mathrm{mal}$ is a lexicalization of long negation and deontic modality. We then address the question of why short negation is impossible in negative imperatives. In section 3, we will consider some alternative approaches and point out their limitations. In section 4, assuming the clause structure of imperatives with two separate projections for modality and force, we propose that a negative imperative with short negation is ruled out because such construction maps onto incoherent interpretation.

By imperatives, we refer to sentences with distinctive imperative morphology on the verb and/or distinctive imperative syntax. They canonically express the directive illocutionary force associated with commands and requests. Consequently, the term IMPERATIVE has often been used to refer to a sentence's function rather than its form. However, we use the term IMPERATIVE to refer exclusively to a sentence's form. For referring to a sentence's function, we use terms such as COMMAND and REQUEST.

\section{Nature of mal}

For an account of the morpho-syntactic nature of mal, we will extend and refine the approach given in (Lee, 1978; Lee, 1979): i.e., 'long negation $+h a$ ' lexicalizes as mal in the context of imperatives.

Tellingly, mal can occur in non-imperatives as well, as long as they form deontic modality contexts. For example, it can occur in matrix clauses that are not imperatives but constitutes a deontic modality context as in (3), and in embedded clauses under directive/volitional verbs as in (4), which can also be deontic modality contexts. Given that imperatives also form deontic modality context, the proper generalization is that ani ha lexicalizes as mal in the context of deontic modality, and not just in the context of the imperative mood.

(3) Matrix clauses

a. Cey-ka hakkyo-ey ka-ci mal-kkayo?

I-Nom school-to go-Ci Neg-Q

'Should I not go to school?'

b. Na-nun hakkyo-ey ka-ci mal-ayakeyss-ta.

I-Top school-to go-Ci Neg-Irrealis-Decl

'I should not go to school.'

(4) Embedded clauses

a. Inho-ka Yumi-eykey hakkyo-ey ka-ci mal-la-ko tangpwuha-yess-ta. Inho-Nom Yumi-to school-to go-Ci Neg-Irrealis-Comp tell-Past-Decl 'Inho told Yumi that he should not go to school.'

b. Inho-nun Yumi-ka hakkyo-ey ka-ci mal-ki-lul pala-n-ta. Inho-Top Yumi-Nom school-to go-Ci Neg-Inf-Acc want-Pres-Decl 'Inho wants Yumi to not go to school.'

This strongly suggests that we need separate categories for deontic modality and the imperative. A further motivation for distinguishing between deontic modality and the imperative is 
that languages in general do not allow embedded imperatives. One may think that Korean allows embedded imperatives, because $l a$ which occurs in imperative verb can also occur in embedded verbs. But on a closer look, the morpheme that occurs in imperative verbs is not exactly the same as the one in embedded verbs.

(5) a. hakkyo-ey ilccik o-ala.

school-to early come-Imp

'Come to school early.'

b. Inho-ka Yumi-eykey hakkyo-ey ilccik o-la-ko cisiha-yess-ta. Inho-Nom Yumi-to school-to early come-Irrealis-Comp tell-Past-Decl 'Inho told Yumi to come to school early.'

c. * Inho-ka Yumi-eykey hakkyo-ey ilccik o-ala-ko cisiha-yess-ta. Inho-Nom Yumi-to school-to early come-Imp-Comp tell-Past-Decl 'Inho told Yumi to come to school early.'

Nevertheless, mal can occur in embedded clauses under directive/volitional verbs. This suggests that what is responsible for licensing $\mathrm{mal}$ is not the category of imperative but the category of deontic modality.

We propose to represent the deontic modality and the imperative mood in the clausal structure of imperatives by positing a projection for the modality and a projection for an imperative operator that encodes illocutionary force.

(6)

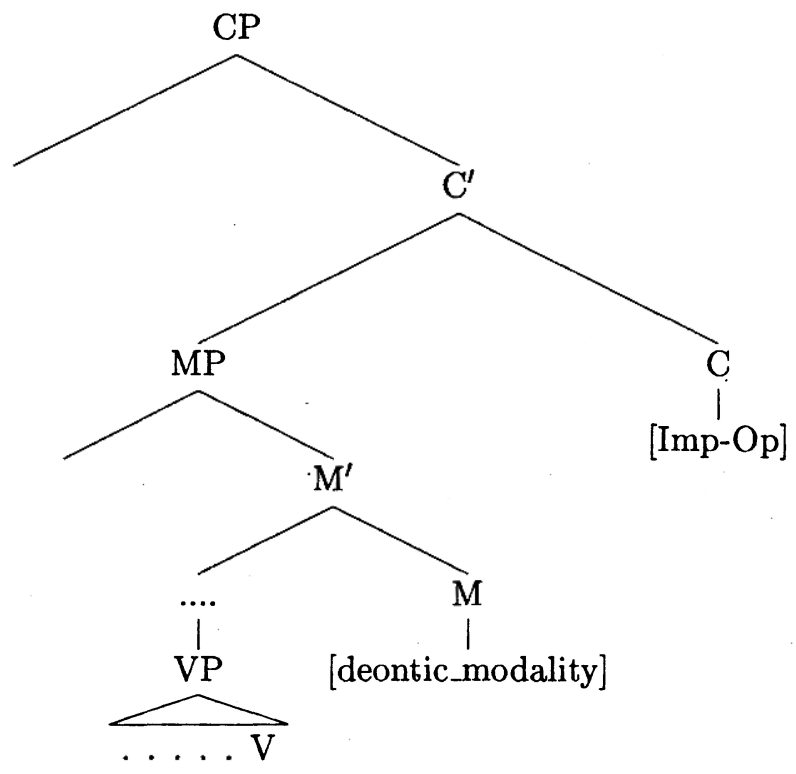

Assuming this structure, we will propose an analysis for why negative imperatives cannot be formed with short negation.

\section{No negative imperatives with short negation: some alternative approaches}

In this section, we turn to the issue of why short negation is impossible in negative imperatives. Before presenting our analysis in section 4 , we consider and reject three possible alternative approaches. 


\subsection{Alternative 1: Short negation requires tense?}

Zanuttini $(1991,1994,1997)$ distinguishes between preverbal negation and postverbal negation in Romance, and argues that preverbal negation requires TP, whereas postverbal negation doesn't.

(7) $[\mathrm{NegP} 1[\mathrm{TP} \ldots[\mathrm{NegP} 2 \ldots[\mathrm{VP} \ldots]]]]$

She further argues that imperatives are tenseless, not projecting TP. Putting the two together, she concludes that imperatives are not compatible with negation in languages that have preverbal negation. (e.g. Italian and Spanish)

We can adopt Zanuttini's system to explain why Korean negative imperatives cannot be formed with short negation, if we can claim that Korean imperatives are tenseless, and that short negation requires tense phrase. While it is reasonable to assume that Korean imperatives are tenseless, it is not correct to claim that short negation requires tense phrase. Negative infinitivals can be formed with short negation as in (8).

$$
\begin{aligned}
& \text { Inho-ka hakkyoey an ka-ki-lul pala-n-ta. } \\
& \text { Inho-Nom school-to Neg go-Inf-Acc want-Pres-Decl } \\
& \text { 'Inho wants not to go to school.' }
\end{aligned}
$$

\subsection{Alternative 2: Short negation as a blocker for verb movement?}

Assuming the following clause structure, Rivero 1994, and Rivero and Terzi 1995 provide an account for why Spanish and Modern Greek do not have negative imperatives, whereas Bulgarian and Serbo-Croatian do.

$$
\text { (9) [CP C [NegP [IP I [VP ...V... ]]]] }
$$

They argue that in Spanish, Modern Greek and Italian, the root $\mathrm{C}^{0}$ hosts a strong imperative mood feature that must be checked by the verb before Spell-out. In imperatives, however, $\mathrm{Neg}^{0}$ blocks imperative verb movement to $\mathrm{C}^{0}$, and so negative imperatives are unavailable in Modern Greek, Spanish and Italian. On the other hand, in Bulgarian and Serbo-Croatian, the strong imperative mood feature is located in $\mathrm{I}^{0}$, rather than in $\mathrm{C}^{0}$. This means that the imperative verb moves only up to $\mathrm{I}^{0}$. Since imperative verbs do not cross $\mathrm{Neg}^{0}$, negative imperatives are available in these languages.

As noted in (Han, 2000; Han, In Press), a drawback of Rivero and Terzi's analysis is that it neglects that in Modern Greek, Spanish and Italian, the morphosyntax of negation is similar to that of clitics. In negative sentences, negation always immediately precedes the main verb, and nothing can intervene between negation and the verb. Negation is very closely associated with the verb, and it is treated as a unit with the verb in overt syntax. If a verb moves to a position higher in the clause in a certain construction, we expect the verb and the negation to move as a unit in the negative counterpart. For instance, in Italian Aux-to-Comp constructions (Rizzi, 1982; Cinque, 1999), where a participle or an infinitive inverts around a subject as in (10a), negation and the verb move to $\mathrm{C}^{0}$ as a unit, in the negative counterpart, as in (10b).

(10) Italian

a. Avendo Gianni fatto questo, ... having Gianni done this, ...

b. Non avendo Gianni fatto questo, ... Neg having Gianni done this, ...

Given this fact, it is not surprising that the verb cannot move across $\mathrm{Neg}^{0}$ in negative imperatives in languages with clitic-like negation. The real puzzle is why the verb cannot move with $\mathrm{Neg}^{0}$ in negative imperatives.

In order to adopt Rivero and Terzi's system, we must show that in Korean, the imperative verb moves to $\mathrm{C}^{0}$, and that short negation is a blocker for this movement. It is difficult to show 
that there is verb movement in Korean because Korean is a verb final language. This means that if there were verb movement at all, it would be a string-vacuous movement. Even if we assume that there is verb movement in Korean, for the sake of argument, it is difficult to establish that short negation blocks verb movement. Short negation shows morphosyntactic properties similar to Romance clitic-like negation, in that it must occur immediately before the main verb. So, it is reasonable to assume that if the verb moved, short negation would move along with it. To capture this tight relationship between short negation and the verb, some have argued that short negation is like a prefixal particle on the verb (Han, 1987; No, 1988; Kim, 2000b).

\subsection{Alternative 3: Short negation negates illocutionary force?}

To account for why some languages do not allow negative imperatives, (Han, 2000; Han, In Press) builds on the intuition that the illocutionary force contributed by the imperative mood cannot be negated. That is, negative imperatives have only the reading in which the directive force has scope over negation, never one which negation has scope over the directive force. This point is illustrated in (11).
a. Don't call!
$\approx$ I require that you not call.
$\not$ I do not require that you call.
b. Nobody leave!
$\approx$ I require that everybody not leave.
$\not$ I do not require that everybody leave.

This intuition was already put forth by Frege, consequently positing that illocutionary force operators cannot be negated (cf., (Frege (see ref.); Dummett 1973). Similar idea was observed in Lee $(1973,1978)$.

Pursuing this idea further, with the assumption that languages have an imperative operator in $\mathrm{C}^{0}$ that canonically contributes illocutionary force, Han argues that some languages like Modern Greek, Spanish and Italian do not allow negative imperatives because when imperative verb moves to $\mathrm{C}^{0}$, it would take along negation with it. But if it did, negation would end up negating the imperative operator in $\mathrm{C}^{0}$, resulting in incoherent interpretation where illocutionary force encoded in the imperative operator is negated.

To apply Han's analysis, we need to show that short negation ends up quite high in the clause structure. If we use declaratives to test where short negation is, it looks like it is low in the clause, in comparison to long negation (Lee 2000). Examples in (12) show that sentences with long negation and a disjunctive phrase only allow a reading in which negation takes scope over the disjunction (De Morgan's law), whereas sentences with short negation allow the reading in which negation takes scope over the disjunction and the reading in which disjunction takes scope over negation. Moreover, in (13), while a conjunctive sentence with long negation allows the reading in which negation negates the first and the second conjuncts, a sentence with short negation does not allow this reading. Given that short negation is not high in the clause, not even as high as long negation, Han's analysis has nothing to say about why Korean negative imperatives cannot be formed with short negation.

(12) a. Inho-ka sakwa-na pae-lul an mek-ess-ta. Inho-Nom apple-or pear-Acc Neg eat-Past-Decl 'Inho did not eat an apple or a pear.' (neg $>$ or) ?'Inho did not eat an apple or Inho did not eat an orange.' (or $>$ neg)

b. Inho-ka sakwa-na pae-lul mek-ci ani ha-ess-ta. Inho-Nom apple-or pear-Acc eat-Ci Neg do-Past-Decl 
'Inho did not eat an apple or an orange.' (neg > or)

*'Inho did not eat an apple or Inho did not eat an orange.' (or $>$ neg)

(13) a. Inho-ka maykcwu-lul masi-ko sushi-lul an mek-ess-ta. Inho-Nom beer-Acc drink-and sushi-Acc Neg eat-Past-Decl

'Inho drank beer and didn't eat sushi.'

*'Inho didn't drink beer and didn't eat sushi.'

b. Inho-ka maykcwu-lul masi-ko sushi-lul mek-ci ani ha-yess-ta.

Inho-Nom beer-Acc drink-and sushi-Acc eat-Ci Neg do-Past-Decl

'Inho drank beer and didn't eat sushi.'

'Inho didn't drink beer and didn't eat sushi.'

'It is not the case that Inho drank beer and ate sushi. (He only did one of the activities.)

\section{No negative imperatives with short negation: our approach}

\subsection{Assumption on negation in clause structure}

The analysis we develop crucially depends on the scope difference between short and long negation. We have seen that short negation takes scope lower in the clause than long negation. Further arguments along these lines can be found in a number of works on Korean negation (cf., (Han and Park, 1994), (Kim, 2000a) and others). The scope difference has led many researchers to posit that there are two possible positions for negation in Korean: i.e., the long form projects or ends up higher up in the clause than the short form.

We will assume a clause structure as in (14), and postulate that long negation starts out as the head of NegP, and short negation is in [Spec, NegP].

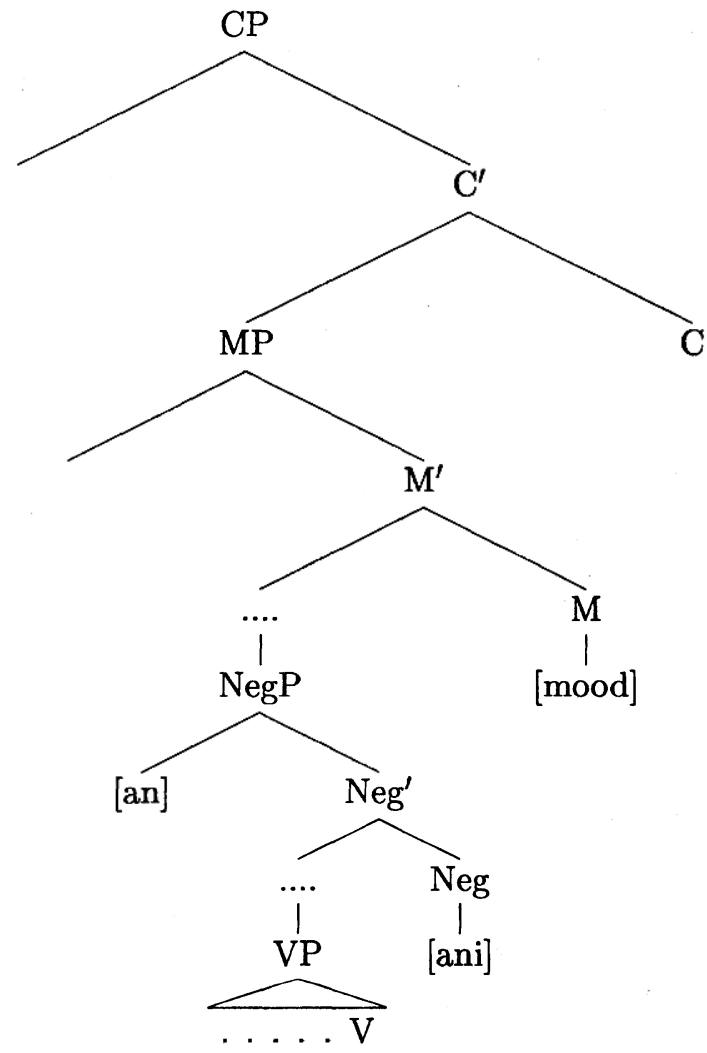


Positing two different positions for long and short negations is supported by the fact that a sentence can contain both types of negation, as in (15).

\author{
Inho-nun maykcwu-lul an masi-ci ani ha-yess-ta. \\ Inho-Nom beer-Acc Neg drink Neg do-Past-Decl \\ 'Inho didn't not drink beer.' \\ 'Inho drank beer.'
}

Moreover, positing a NegP and placing long negation as the head of NegP is motivated by the fact that the verb must be inflected with - $c i$, which is an instantiation of selectional requirement imposed on a head by another head, and that $h a$, which is equivalent to English do, is required to support tense and mood because $a n i$ in $\mathrm{Neg}^{0}$ blocks the verb from coming together with tense and mood inflections.

We further assume that long negation cliticizes to $h a$, eventually ending up in $\mathrm{M}^{0}$. This is consistent with the fact that long negation takes scope higher in the clause than short negation.

\title{
4.2 Why can't negative imperatives be formed with ani ha?
}

Recall the discussion from section 2 that $m a l$ is a lexicalization of 'long negation + deontic modality'. This predicts that mal should show similar scope property as long negation ani. The prediction is borne out by the fact that in a negative imperative with a disjunctive phrase, only the reading in which negation takes scope over the disjunction is available (an instantiation of De Morgan's law), as shown in (16). As was shown in (12b), sentences containing a disjunctive phrase and long negation ani show the same scope property.

(16) pae-na sakwa-lul mek-ci mal-ala!

pear-or apple-Acc eat-Ci Neg-Imp

'Don't eat a pear or an apple!' ( $\sqrt{ } \mathrm{Neg}>$ or, ${ }^{*}$ or $\left.>\mathrm{Neg}\right)$

The implementation of this idea is straightforward in distributed morphology framework (Halle and Marantz, 1993; Halle and Marantz, 1994). In distributed morphology, nodes in syntax dominate feature bundles, and lexical insertion takes place later in the derivation, in the morphological component. That is, in negative imperatives, once all the movements have taken place, $\mathrm{M}^{0}$. will dominate a feature bundle that contains a feature for negation, and a feature for deontic modality. In the morphological component, the vocabulary item that matches the most number of features is inserted under a syntactic node. And more specified vocabulary item blocks less specified vocabulary items for lexical insertion (Blocking Principle). The idea is that mal is more specified than regular long negation $a n i$, hence $m a l$ is inserted in negative imperatives (and other deontic modality contexts), instead of ani.

\subsection{Why can't negative imperatives be formed with an $V$ ?}

We can now turn to the question of why short negation is impossible in negative imperatives. One possible approach is to stipulate that negative sentences containing mal projects MoodP of deontic modality, while those containing long form ani or short form an do not. ${ }^{1}$ And since imperatives require a projection of deontic modality, they must form negation with mal. However, if negative imperatives must project MoodP of deontic modality, so should affirmative imperatives. But then clearly, they can do so without the presence of mal. This means that projection of deontic modality in imperatives is independent from the lexical form of negation. Long negation ani can be ruled out in negative imperatives by Blocking Principle as sketched in section 4.2, but the same mechanism cannot be applied to rule out short negation an.

\footnotetext{
${ }^{1}$ We thank a PACLIC 16 reviewer for suggesting that we consider this approach.
} 
The starting point of our analysis is the meaning of imperatives, which we argue can be spelled out as I direct you to bring about a state or an event. And a negative imperative means I direct you to not bring about a state or an event. Assuming the clause structure in (6) for imperatives, we argue that the imperative operator is responsible for contributing I order you part, and the deontic modality is responsible for contributing to bring about part. The imperative operator takes the widest scope, taking scope over the deontic modality, which in turn takes scope over the propositional content contributed by the clause. For instance, the propositional content of the affirmative imperative in (17a) is as in (17b). Its logical form can be represented as in (17c), and its meaning can be spelled out as in (17c).

(17) a. Mwun-ul yel-ela. door-Acc open-Imp

'Open the door!'

b. P: you open the door

c. $\operatorname{Imp}(\operatorname{deontic}(\mathrm{P}))$

d. I direct you to bring about the situation of the door being open.

As for negative imperatives, assuming a clause structure as in (14) and that long negation ends up in $\mathrm{M}^{0}$, and assuming that $m a l$ is a lexicalization of 'long negation + deontic modality', we propose that mal maps onto the interpretation where deontic modality is negated. That is, long negation occurs high enough in the clause so that it can negate the component contributing to bring about, resulting in the interpretation to not bring about a state or an event. This will give us the interpretation of negative imperatives as spelled out in (18).

(18) a. Mwun-ul yel-ci mal-ala. door-Acc open-Ci Neg-Imp

'Don't open the door!'

b. P: you open the door

c. $\quad \operatorname{Imp}(\neg \operatorname{deontic}(\mathrm{P}))$

d. I direct you to not bring about the situation of the door being open.

Short negation on the other hand is lower in the clause, lower than the projection of deontic modality. We propose that this has effect on meaning. That is, if a negative imperative were to be formed with short negation, then short negation would not be able to negate the part contributing to bring about. It would only negate the state or the event contributed by the propositional content. An imperative with short negation then would result in the interpretation I order you to bring about a negative state or a negative event. But this is incoherent and so negative imperatives with short negation are ruled out. An illustration is given in (19).
a. * Mwun-ul an yel-ela.
door-Acc Neg open-Imp
'Don't open the door!'
b. P: you do not open the door
c. $\quad \operatorname{Imp}(\operatorname{deontic}(\neg \mathrm{P}))$
d. \# I direct you to bring about the situation of you not opening the door. 


\subsection{Acquisition data}

(Lee, 1988) points out that young kids sometimes produce negative imperatives with short negation, providing the following naturally-occurring sentence as an example.

$$
\begin{aligned}
& \text { an ka! } \\
& \text { Neg go , } \\
& \text { 'Don't go!' }
\end{aligned}
$$

There are works in psycholinguistics that argue that Korean kids acquire short negation before long negation. (Park, 1998) shows that 3 year-olds in general do not produce long negation only producing short negation, whereas 5 year-olds can produce both short and long negation. Park shows that while 3 year-olds used short negation when repeating after an adult sentence with long negation, 5 year-olds used long negation in the same situation.

In our analysis, mal is a lexicalization of long form negation. Thus, the fact that kids are using short negation instead of mal fits in with the findings in acquisition literature. It looks like kids who have not yet acquired long negation are using short negation in imperatives to express negative commands. It may be that kids who have not yet acquired long negation associate wider range of interpretational possibilities with short negation, hence allowing short negation in negative imperatives. Exactly what mechanism allows this remains as a question.

\section{Conclusion}

To conclude, we have argued that imperatives project a projection of deontic modality and a projection of the imperative operator contributing the illocutionary force. Assuming this clause structure, we proposed that mal in negative imperatives is a lexicalization of long form negation and deontic modality. Assuming further that long and short negation occur in two different positions in the clause structure, we proposed that a negative imperative with short negation ends up with an interpretation in which the event or the state contributed by the propositional content is negated, resulting in an incoherent interpretation. No such problem occurs with mal because mal is a lexicalization of long negation, which negates the deontic modality. Given the proposed analysis, the incompatibility of short negation and imperatives in Korean is another case that shows that the set of available syntactic structures in a language is restricted by the semantics. In future work, we would like to explore the feasibility of extending our analysis to other languages that do not allow negative imperatives, such as Italian, Spanish, and Modern Greek.

\section{References}

Cinque, Guglielmo. 1999. Adverbs and Functional Heads : A Cross-Linguistic Perspective. Oxford Studies in Comparative Syntax. Oxford University Press, New York, Oxford.

Dummett, Michael. 1973. Frege: Philosophy of Language. Harper \& Row, New York, Evanston, San Francisco, London.

Halle, Morris and Alec Marantz. 1993. Distributed morphology and the pieces of inflection. In Kenneth Hale and S. Jay Keyser, editors, The View from Building 20. MIT Press, Cambridge, pages 111-176.

Halle, Morris and Alec Marantz. 1994. Some key features of distributed morphology. In Andrew Carnie and Heidi Harley, editors, MIT Working Papers: Papers on Phonology and Morphology, volume 21. MITWPL, Cambridge, pages 275-288.

Han, Chung-hye. 2000. The Structure and Interpretation of Imperatives: Mood and Force in Universal Grammar. Outstanding Dissertations in Linguistics. Garland Publishing, New York. 
Han, Chung-hye. In Press. Force, negation and imperatives. The Linguistic Review. To appear in 12:4, 2001.

Han, Haksung. 1987. The Configurational Structure of the Korean Language. Ph.D. thesis, University of Texas, Austin.

Han, Ho and Myung-Kwan Park. 1994. The syntax of negation in korean and iţs development in child language. In Proceedings of ESCOL, pages 152-162.

Kim, Ae-Ryung. 2000a. Two positions for korean negation. In Japenese/Korean Linguistics, volume 10. CSLI, Stanford.

Kim, Jong-Bok. 2000b. Prefixal short negation. In Harvard Studies in Korean Linguistics, volume VIII. Dept. of Linguistics, Harvard University, pages 403-418.

Lee, Chung-Min. 1979. Negative imperatives in korean. Korean Journal, 2:48-52.

Lee, Chungmin. 1978. Negative imperatives in korean. In Chin-Woo Kim, editor, Papers in Korean Linguistics. Hornbeam Press, Comlubia, South Carolina, pages 149-156.

Lee, Chungmin. 1988. Speech act terms and mood indicators (in korean). Acta Linguistica Hungarica, 38:127-141.

No, Yongkyoon. 1988. Negative morphemes in korean. In Proceedings of the 6th International Circle of Korean Linguistics.

Park, Heeheon. 1998. Acquisition of negation in korean. Korean Linguistics: Journal of the International Circle of Korean Linguistics, 9:111-131.

Rivero, Maria-Luisa. 1994. Negation, imperatives and wackernagel effects. Rivista di Linguistica, 6(1):39-66.

Rivero, Maria-Luisa and Arhonto Terzi. 1995. Imperatives, v-movement and logical mood. Journal of Linguistics, 31:301-332.

Rizzi, Luigi. 1982. Issues in Italian Syntax. Foris, Dordrecht.

Zanuttini, Raffaella. 1991. Syntactic properties of sentential negation: a comparative study of Romance languages. Ph.D. thesis, University of Pennsylvania.

Zanuttini, Raffaella. 1994. Speculations on negative imperatives. Rivista di Linguistica, 6(1):67-89.

Zanuttini, Raffaella. 1997. Negation and clausal structure: a comparative study of Romance languages. Oxford Studies in Comparative Syntax. Oxford University Press, New York, Oxford. 